\title{
Prolonged QT period in diabetic autonomic neuropathy: a possible role in sudden cardiac death?
}

\author{
F Bellavere, M FERRI, L GUARINI, G BAX, A PICCOLI, C CARDONE, \\ D FEDELE
}

\section{From the Istituto di Medicina Interna, Cattedra di Patologia Medica Policlinico, Padua, Italy}

SUMMARY Twenty four men with insulin dependent diabetes and different degrees of autonomic neuropathy were studied to establish the response of the QT interval to various heart rates. Nine men with autonomic neuropathy had a longer QT interval than 13 healthy individuals and 15 patients who had diabetes without, or with only mild, autonomic neuropathy. Those with autonomic neuropathy also had a proportionally greater lengthening of the QT interval for a given increase in RR interval.

The results of this study suggest a basis for the finding that sudden death is more common in patients with diabetic autonomic neuropathy.

An association between an abnormal QT interval and sudden cardiac death has been found in various diseases. ${ }^{12}$ The influence of autonomic tone on the QT period is also widely accepted, although the mechanisms underlying the shortening or lengthening of this period are still not clear. ${ }^{34}$

In the late 1970 s several reports noted the high incidence of sudden death in diabetic patients who had severe autonomc neuropathy. ${ }^{56}$ In some cases death was attributed to cardiorespiratory arrest, but in the overwhelming majority the cause of death was not identified.

This prompted us to investigate changes in QT interval during static (quiet lying, sitting, and standing) and dynamic (Valsalva manoeuvre) conditions in groups of diabetic patients with different degrees of autonomic neuropathy.

\section{Patients and methods}

The diabetic patients (men aged (mean (SD)) $42(12)$ ) were subdivided into three groups: eight without autonomic neuropathy, seven with borderline autonomic neuropathy, and nine with definite autonomic neuropathy confirmed by their cardiovascular response to a series of autonomic tests (Valsalva manoeuvre, deep breathing, change of position from lying to standing, sustained hand grip, fall in blood pressure on standing) recommended by Ewing et al

Requests for reprints to Dr F Bellavere, Istituto di Medicina Interna, Cattedra di Patalogia Medica, Via Giustiniani 2, 35100 Padua, Italy.

Accepted for publication 22 October 1987 and scored by a specially devised system. ${ }^{8}$ All the patients had been admitted to the ward for tests to evaluate metabolic control and complications. Their metabolic control was acceptable (glycosylated haemoglobin mean $(\mathrm{SD})$ value $=9 \cdot 2(1) \%$ and their electrolyte balance (sodium, potassium, chloride, calcium, phosphorus, and magnesium) was within the normal range. None had electrocardiographic evidence of, or a history of, cardiovascular disease. The control group consisted of 13 healthy men aged 37 (8) years.

\section{METHODS}

Electrocardiograms were recorded at $25 \mathrm{~mm} / \mathrm{s}$. The QT and RR intervals were measured on a three channel ECG trace over a randomly selected segment of ten beats after three periods of at least two minutes of lying, sitting, and standing. For each position we took the mean of three similar beats in the three recordings as the baseline values. $Q T$ and $R R$ intervals were then measured in each subject during three Valsalva manoeuvres at maximum tachycardia induced on forced expiration (phase 2) and maximum bradycardia after expiration (phase 4). We calculated the mean of three values obtained for each heart rate. The Valsalva manoeuvres were performed in standardised conditions - that is by blowing into a dynamometer for 15 seconds at $40 \mathrm{~mm} \mathrm{Hg}$. ' The Valsalva ratio was calculated (longest $R R$ in phase 4: shortest $R R$ in phase 2). The QT interval was measured carefully according to the guidelines of Simonson et al. ${ }^{10}$ We calculated the corrected QT interval (QTc) for each heart rate by Bazett's formula $(\mathrm{QTc}=\mathrm{QT} / \sqrt{\mathrm{RR}})$. 
STATISTICAL ANALYSIS

We used Student's tests for paired and unpaired data. Analysis of covariance was applied to the regression slopes between QT (dependent variable) and RR (covariate) for the four groups studied. We used program P1V of the Biomedical Computer Programs statistical package for these calculations. ${ }^{11}$

\section{Results}

\section{STATIC ANALYSIS}

Figure 1 shows that the QT interval during quiet sitting, even when uncorrected for heart rate, was significantly longer in diabetic patients with autonomic neuropathy than in healthy individuals ( 360 (30)) $\mathrm{ms}$ vs $340(10) \mathrm{ms}, \mathrm{p}<0.05$ when the RR interval was $750(90) \mathrm{ms}$ vs $824(80) \mathrm{ms}$ respectively (NS). During quiet standing the QT interval was significantly longer in diabetic patients with autonomic neuropathy than in those without autonomic neuropathy (350 (20) ms vs 320 (30) ms (p < 0.05)) when the RR interval was 751 (100) $\mathrm{ms}$ vs 712 (78) ms respectively (NS) and in the controls QT $320(10) \mathrm{ms}$ $(\mathrm{p}<0.01)$ when the RR interval was $770(100) \mathrm{ms}$ (NS). Figure 1, however, also shows that in all cases the QTc interval was significantly longer in diabetic patients with autonomic neuropathy than in those $c$ without and in controls during lying, sitting, and standing.

DYNAMIC ANALYSIS

Figure 2 shows the distribution of QT values in relation to $R R$ values for each group examined at rest $\propto$ maximal tachycardia of phase 2, and maximaks bradycardia of phase 4 during the Valsalva man $\overrightarrow{0}$ oeuvre. Linear regression analysis of the distribution of $Q T$ and $R R$ values in all groups gave the regression $\vec{\omega}$ equation $y=b x+a$. The regression coefficient for the diabetic patients with autonomic neuropathy $(b=0.22, a=193, r=0.824)$ was significantly different from that of the diabetic patients without $\omega$ autonomic neuropathy, with borderline autonomicy neuropathy, and controls ( $p<0.0001)$. Regressiono coefficients in the last three groups were not significantly different from one another $(b=0.086$, az $=260, \mathrm{r}=0.807 ; \mathrm{b}=0.107, \mathrm{a}=253, \mathrm{r}=0.881$; and $\mathrm{b}=0.083, \mathrm{a}=272, \mathrm{r}=0.815$ respectively).

As expected fig 2 shows that the variation of $R_{R}$

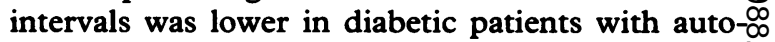
nomic neuropathy (mean Valsalva ratio $1.18(0 \cdot 10))$ (table). The difference between the slope of the diabetic patients with autonomic neuropathy was
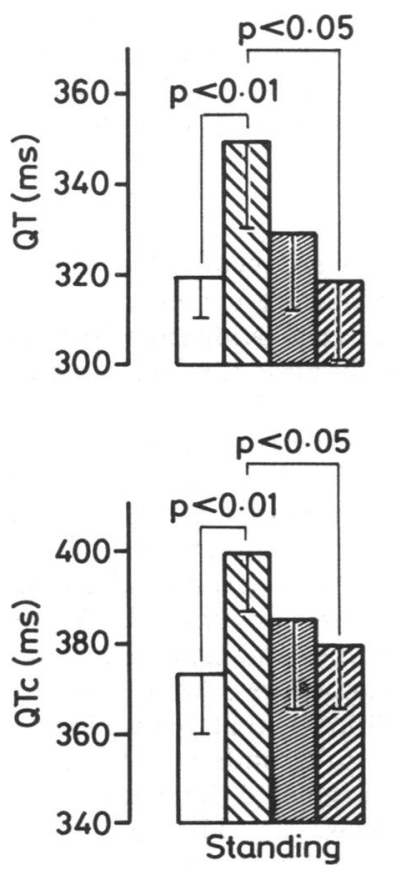
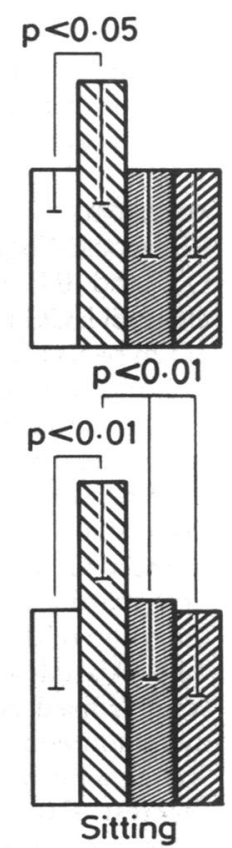
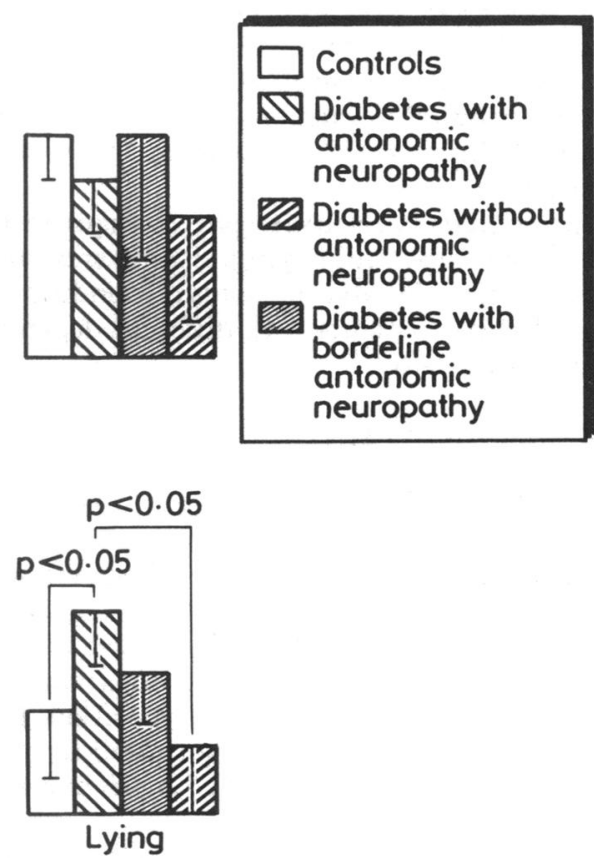

Fig 1 Mean values ( $m s$ ) for $Q T$ and $Q T c$ intervals during quiet standing, sitting, and lying in 13 controls, nine diabetic patients with autonomic neuropathy, seven diabetic patients with borderline autonomic neuropathy, and eight diabetic patients without autonomic neuropathy. 


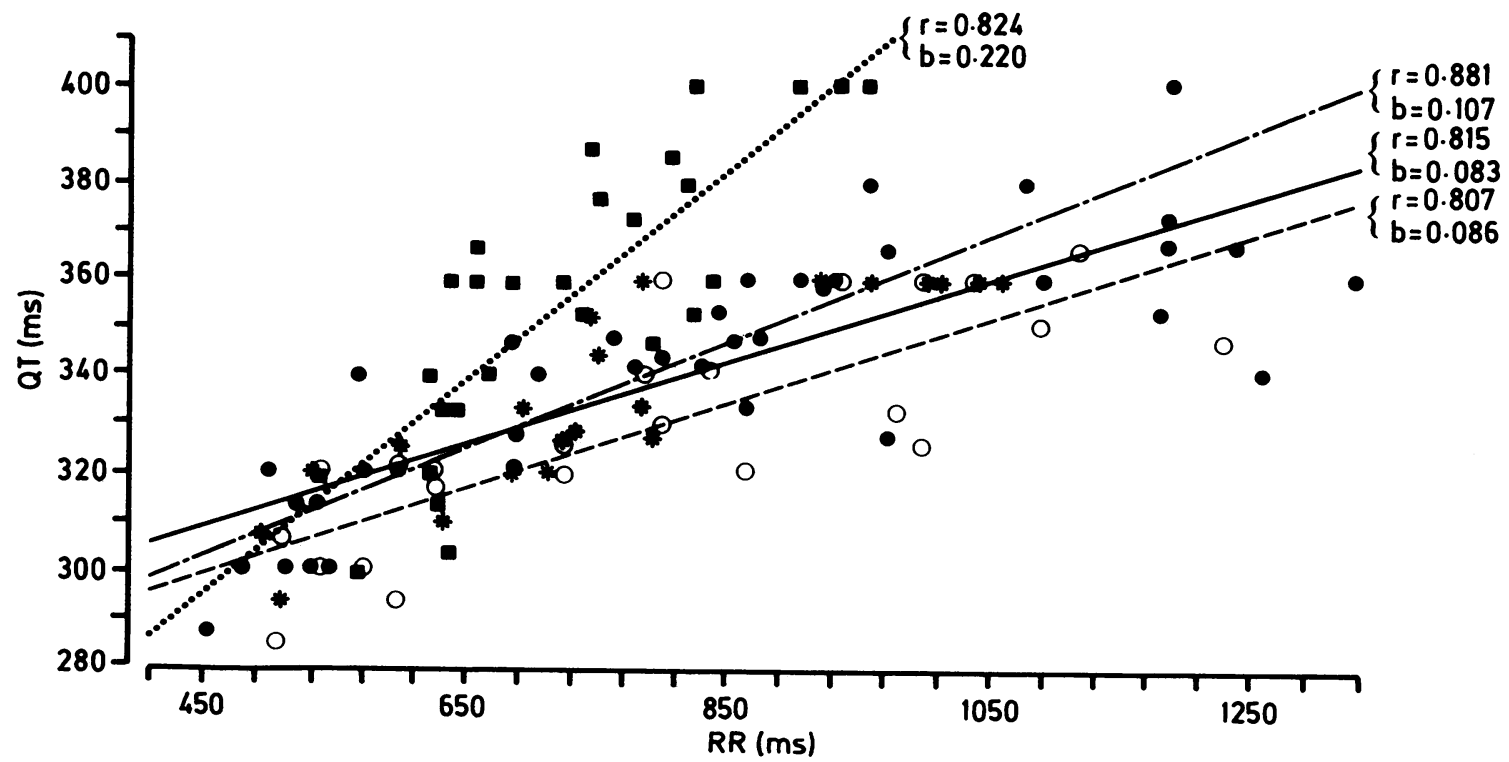

Fig 2 Regression lines for mean individual $Q T$ vs $R R$ intervals in phase 2, resting, and phase 4 of Valsalva manoeuvre in 13 controls ( - ) , eight diabetic patients without autonomic neuropathy $(\mathrm{O}--\mathrm{O})$, seven diabetic patients with

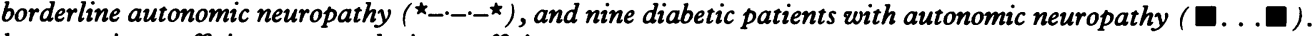
$b$, regression coefficient; $r$, correlation coefficient.

highly significant $(F=9.02, p<0.0001)$ from the cumulative slope of the other three groups (fig 3 ). ${ }^{11}$ These three groups may be viewed as having a common regression line $(b=0.088 ; a=265$, $r=0.814$ ) because there was no significant difference $(F=0.80)$ between their individual regression lines.

\section{Discussion}

The data clearly show that the relation between QT and $R R$ intervals is altered under both static and dynamic conditions in diabetic patients with overt autonomic neuropathy. The importance of the autonomic influence in determining the QT interval is well established. ${ }^{3412}$ Because there was no other apparent cause to explain the abnormal lengthening of the QT interval in our diabetic patients with autonomic neuropathy, it seems reasonable to attribute this to a disturbance of the autonomic regulation of myocardial repolarisation.

The mechanism underlying this alteration is not easily explained. It is generally agreed that the parasympathetic system has little, if any, direct effect on QT modulation, which is widely attributed to

tble Mean group values of $R R$ and related $Q T$ intervals (ms) at maximum tachycardia (in phase 2 ) and at resting and maximum adycardia (in phase 4) measured during three Valsalva manoeuvres in 13 controls, eight diabetic patients without autonomic neuropathy, jen diabetic patients with borderline autonomic neuropathy, and nine diabetic patients with autonomic neuropathy

\begin{tabular}{|c|c|c|c|c|c|c|c|c|}
\hline & \multirow[b]{2}{*}{ No } & \multicolumn{2}{|c|}{ Tachycardia } & \multicolumn{2}{|l|}{ Resting } & \multicolumn{2}{|l|}{ Bradycardia } & \multirow[b]{2}{*}{ Valsalva ratio } \\
\hline & & $R R$ & $Q T$ & $R R$ & $Q T$ & $R R$ & $Q T$ & \\
\hline $\begin{array}{l}\text { Controls } \\
\text { Diabetes without autonomic neuropathy } \\
\text { Diabetes with borderline autonomic } \\
\text { neuropathy }\end{array}$ & $\begin{array}{r}13 \\
8 \\
7\end{array}$ & $\begin{array}{l}554(73) \\
562(44) \\
614(110)\end{array}$ & $\begin{array}{l}315(18) \\
305(13) \\
318(14)\end{array}$ & $\begin{array}{l}824(77) \\
812(111) \\
793(137)\end{array}$ & $\begin{array}{l}344(12) \\
337(16) \\
340(19)\end{array}$ & $\begin{array}{r}1119(132) \\
1009(115) \\
901(139)\end{array}$ & $\begin{array}{l}364(18) \\
344(18) \\
349(18)\end{array}$ & $\begin{array}{l}2.06(0.37) \\
1.80(0.28) \\
1.47(0.30)\end{array}$ \\
\hline Diabetes with autonomic neuropathy & 9 & $660(84)$ & $347(31)$ & $750(97)$ & $358(29)$ & $779(121)$ & $365(30)$ & $1 \cdot 18(0 \cdot 10)$ \\
\hline $\begin{array}{l}\mathrm{a} v s \mathrm{~b} \\
\mathrm{a} v s \mathrm{c} \\
\mathrm{a} v s \mathrm{~d} \\
\mathrm{~b} v s \mathrm{c} \\
\mathrm{b} v s \mathrm{~d} \\
c v s \mathrm{~d}\end{array}$ & & $\begin{array}{l}\text { NS } \\
\text { NS } \\
<0.01 \\
\text { NS } \\
<0.01 \\
\text { NS }\end{array}$ & $\begin{array}{l}\text { Significa } \\
= \\
= \\
= \\
-\end{array}$ & $\begin{array}{l}\text { sting } \\
\text { NS } \\
\text { NS } \\
\text { NS } \\
\text { NS } \\
\text { NS } \\
\text { NS }\end{array}$ & $\begin{array}{l}E \\
z \\
z\end{array}$ & $\begin{array}{l}\text { NS } \\
<0.05 \\
<0.001 \\
\text { NS } \\
<0.005 \\
\text { NS }\end{array}$ & $\begin{array}{l}z \\
z \\
z\end{array}$ & $\begin{array}{l}\text { NS } \\
<0.005 \\
<0.001 \\
\text { NS } \\
<0.001 \\
<0.05\end{array}$ \\
\hline
\end{tabular}


382

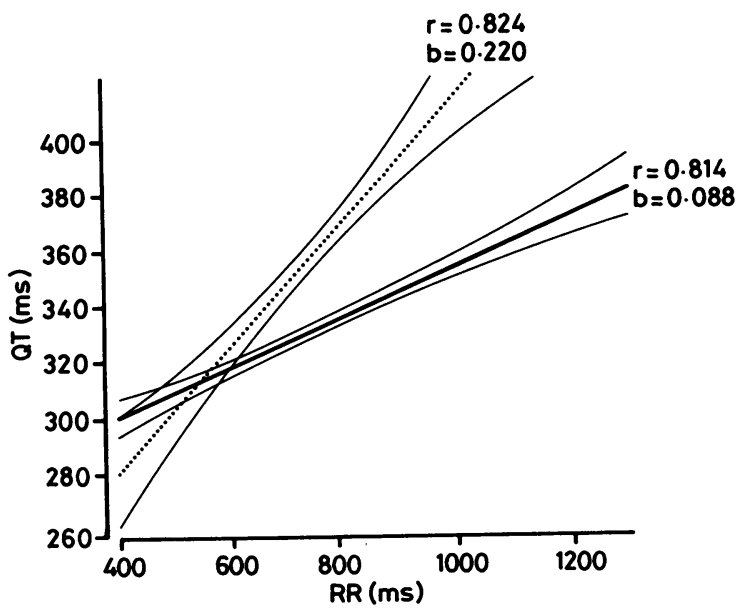

Fig 3 Regression lines and confidence intervals for $Q T$ vs $R R$ intervals during the Valsalva manoeuvre in nine diabetic patients with autonomic neuropathy (....) and in all the remaining subjects (- $). b$, regression coefficient; $r$, correlation coefficient.

sympathetic influence ${ }^{34}$ and recent evidence suggests that the left efferent cardiac sympathetic fibres may influence QT interval. ${ }^{2}$

In our patients it is difficult to propose a sound hypothesis for the effective mechanism underlying lengthening of the QT interval because diabetic patients with autonomic neuropathy show a pattern of overriding parasympathetic withdrawal followed by a sympathetic deficiency which at present is difficult to evaluate in clinical practice. Because the parasympathetic pathway does not appear to operate in these patients, we agree with recent reports that some non-quantifiable sympathetic imbalance is responsible for the abnormal lengthening of the QT interval in our patients. Evidence suggests that in diabetic patients with autonomic neuropathy the prolonged mean values for QT interval resemble (for example $Q T=362 \mathrm{~ms}$ for an $R R=750 \mathrm{~ms}$, that is $\mathrm{QTc}=413 \mathrm{~ms}$ during quiet sitting) those found in patients with the so-called "long QT syndrome", a condition in which there is a high risk of sudden cardiac death. ${ }^{2}$

In the late 1970s there were several reports that unexpected sudden death was common in diabetic patients with autonomic neuropathy.$^{67}$ In some cases this was attributed to a respiratory arrest. But this was confirmed as the cause of death in only two cases and no explanation could be found for the remaining cases. Since then evidence has tended to argue against the hypothesis of simple respiratory arrest as the cause of death, because no alteration in the response to hypoxia or hypercapnia has been found in patients with autonomic neuropathy. ${ }^{1314}$

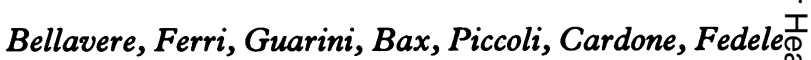

Analysis of our data on QT adaptation to $R_{C} \stackrel{\frac{\varrho}{7}}{C}$ variation during dynamic conditions (fig 2) shows that the QT interval was similar in all diabetic $\stackrel{\text { ? }}{?}$ patients and controls at the lowest values of $R R$ C (induced tachycardia) but that as the $R R$ interval $\frac{}{=}$ lengthened, the QT interval tended to increase $\frac{\bar{c}}{\sigma}$ proportionally more in patients with autonomic $\propto$ neuropathy until highly abnormal values of $>400 \mathrm{~ms}$ were reached when the $R R$ interval was $1000 \mathrm{~ms} \vec{\circ}$ (heart rate $=60$ beats $/ \mathrm{min}$ ).

There was a tendency towards tachycardia in the $\overrightarrow{\vec{\omega}}$ patients with diabetic autonomic neuropathy and $\frac{\mathscr{}}{5}$ none had a resting heart rate as low as 60 beats $/ \mathrm{min}$. But even in patients with autonomic neuropathy of some interventions, such as drug treatment and $\omega$ anaesthesia, can lower the heart rate. Most sudden $\omega_{U}^{\omega}$ deaths in such patients occur during the induction of anaesthesia, which commonly provokes pronounced bradycardia, a condition which greatly increases the $\vec{z}$ risk of cardiac arrest even in healthy subjects. ${ }^{15}$

In 1984 we suggested that the increase in QT interval that we found in diabetic patients with $\vec{\varphi}$ autonomic neuropathy might explain their high risk $\infty_{\infty}^{\circ}$ for sudden death. ${ }^{16}$ The current study and another ${ }^{17}$ support this view.

Should autonomic diabetic cardiac neuropathy be included among the long QT syndromes and could the altered relation between $Q T$ interval and $R R \frac{D}{\Phi}$ interval in such patients explain the high incidence of $\propto$ sudden unexpected death in these patients? We hope $\overline{\bar{O}}$ that studies such as ours will lead to an answer.

\section{References}

1 Vlay SC, Mallis GI, Brown EJ, Cohn PF. Documented sudden cardiac death in prolonged Q-T syndrome. Arch Intern Med 1984;144:833-4.

2 Schwartz PJ. Idiopathic long Q-T syndrome: progress

3 Browne KF, Prystowsky E, Heger JJ, Chilson DA, Zipes DP. Prolongation of the Q-T interval in mano during sleep. Am J Cardiol 1983;52:55-9.

4 Ahnve $S$, Vallin $H$. Influence of heart rate and $N$ inhibition of autonomic tone on the Q-T interval. $\mathrm{N}$ Circulation 1981;65:435-9.

5 Page M, Watkins PJ. Cardiorespiratory arrest and ${ }^{\omega}$ diabetic neuropathy. Lancet 1978;i:14-6.

6 Pont A, Rushing JL, Kelsay T, Jacobs L. Cardio respiratory arrest and diabetic autonomicg neuropathy. Lancet 1978;i:386-7.

7 Ewing DJ, Campbell IW, Clarke BF. The naturato history of diabetic autonomic neuropathy. $Q J M e d \bar{b}$ 1980;49:95-108.

8 Bellavere F, Bosello G, Fedele D, Cardone C, Ferri M $\frac{9}{\mathbb{D}}$ Diagnosis and management of diabetic autonomic neuropathy. Br Med J 1983;287:61.

9 Ewing DJ. Cardiovascular reflexes and autonomig 

neuropathy. Clin Sci 1978;55:321-7.

10 Simonson E, Cady LD, Woodbury M. The normal Q-T interval. Am Heart J 1962;63:747-53.

11 Dixon WJ, Brown MB, Engelman L, et al. BMDP statistical software. Berkeley: UCLA, 1981.

12 Bexton RS, Vallin HO, Camm AJ. Diurnal variation of the QT interval-influence of the autonomic nervous system. Br Heart J 1986;55:253-8.

13 Rees PJ, Prior JG, Cochrane JM, Clark TJH. Sleep apnoea in diabetic patients with autonomic neuropathy. JR Soc Med 1981;74:192-5.

14 Catteral JR, Calverley PMA, Ewing DJ, Shapiro CM, Clarke BF, Douglas NJ. Breathing, sleep, and diabetic autonomic neuropathy. Diabetes 1984;33: 1025-7.

15 Keenan RL, Boyan P. Cardiac arrest due to anesthesia. JAMA 1985;253:2373-7.

16 Bellavere F, Ferri M, Cardone C, Guarini L, Bosello G, Fedele D. The analysis of $Q T$ versus RR ECG interval variations in diabetic patients shows a longer QT period in subjects with autonomic neuropathy. XX EASD Annual Meeting, 12-15 September 1984, London. Diabetologia 1984;27:255A.

17 Kahn K, Sisson JC, Vinik AI. QT interval prolongation and sudden cardiac death in diabetic autonomic neuropathy. J Clin Endocrinol Metab 1987;64:751-4. 